Journal of Engineering and Applied Sciences 14 (5): 1645-1648, 2019

ISSN: 1816-949X

(C) Medwell Journals, 2019

\title{
Data Analytics and Philosophy in Dealing with Conflicts
}

\author{
${ }^{1}$ Nazrul Anuar Nayan and ${ }^{2}$ Khairul Anuar A. Rahman \\ ${ }^{1}$ The Institute of Islam Hadhari, \\ Center for Integrated Systems Engineering and Advanced Technologies, \\ Faculty of Engineering and Built Environment, Universiti Kebangsaan Malaysia (UKM), Bangi, \\ Selangor, Malaysia \\ ${ }^{2}$ Department of Electronics and Computer Technology, Faculty of Engineering Technology, \\ Universiti Teknikal Malaysia Melaka, Melaka, Malaysia
}

\begin{abstract}
Religion and science had little distinction during the Golden Age of Islam from the 9-12th century. However, boundaries between these concepts emerged after Darwin's theory of evolution and Napoleon's French revolution. People started to believe that science is more important and superior than religion. This paper discusses the data analytics method used by statisticians such as the $95 \%$ confidence level. Based on literature, researchers proved that respiratory rate is highly predictive of health deterioration. This study then proves that the scientific data of respiratory rate obtained through Electrocardiogram (ECG) can be used to gain information about the health deterioration of patients. We conclude that science has always been used to bolster the knowledge of Allah delivered through his messenger. In other words, religious knowledge might speak to human needs that scientific theories cannot satisfy and finally explain the saying, "Religion without science is superstition and science without religion is materialism."
\end{abstract}

Key words: Data analytics, Islamic knowledge, science, the heart, respiratory rate, electrocardiogram, health deterioration

\section{INTRODUCTION}

Islamic expansion from the 9-12th century during the era of Al-Khilafatu Al-'Abbasiyah witnessed a scientific revival characterized by great advances in mathematics, philosophy, medicine and astronomy made by the will of Allah (Falagas et al., 2006). Baghdad became the center of the Golden Age of Islam. Little distinction was observed among philosophy, science and theology and almost no sign of conflict was found between religion and science. Islam encourages its believers to seek knowledge. The Messenger of Allah said, "Seeking knowledge is an obligation upon every Muslim" (Ibn Majah).

However, the prominence of science rose and the perception of religion in Europe changed in the mid-19th after the emergence of Darwin's evolutionary theory (Paul, 2005) and Napoleon's French revolution which advocated secularism. An apprehensive relationship always existed between religion and science wherein one side or the other is in ascendancy. People started to believe that science is more important than religion. This belief resulted in the increase of secularization and weakening of religion. Science was viewed as a vehicle of social and intellectual liberation. The rational methods of explaining things as demonstrated by scientists were proven superior at obtaining the truth about the natural world.

This study aims to discuss and present an example that proves that science can promote knowledge of Allah and solve the problems we are facing in daily life. Statistician models that are believed to be rational and offer probabilities show their belief in God's power. This study uses data on electrical signals from the human heart, namely, ECG and its relation to respiratory rate.

Statistics: Carl Friedrich Gauss was a German known as the "Prince of Mathematicians" in the 19th century. One day, his assistants were conducting astronomical measurements but they were unable to exactly replicate their results. Gauss got angry and stormed into the laboratory to show these people how to perform

Corresponding Author: Nazrul Anuar Nayan, The Institute of Islam Hadhari,

Center for Integrated Systems Engineering and Advanced Technologies,

Faculty of Engineering and Built Environment, Universiti Kebangsaan Malaysia (UKM), Bangi,

Selangor, Malaysia 


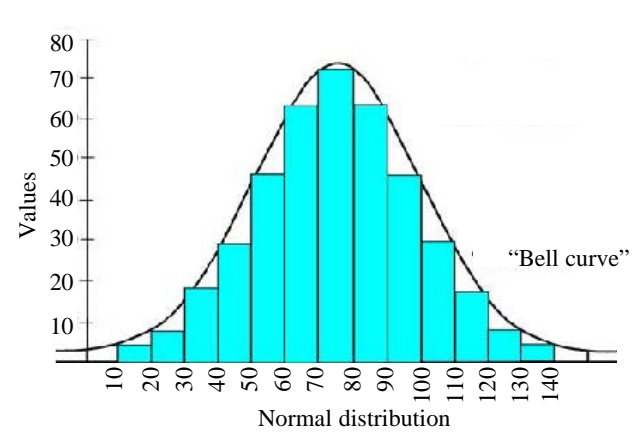

Fig. 1: Normal distribution

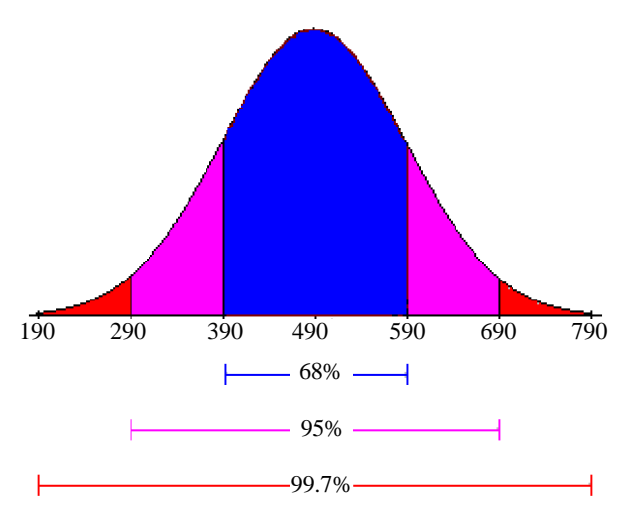

Fig. 2: Standard deviation

measurements correctly but Gauss was not able to repeat his measurements exactly either. After recovering his composure, Gauss created a histogram of measurement results which enabled him to discover the famous Gaussian or bell-shaped curve shown in Fig. 1. This histogram allows us to ask: What could we understand from statistics? We will never obtain $100 \%$ accurate results. Statistics normally include a 95\% confidence level in probability statement to give space for doubt or the will of Allah. The results in the Gaussian or normal distribution include the population mean, median, mode, variance and standard deviation if the experiment is repeated.

The graph in Fig. 2 shows that $68 \%$ falls within one standard deviation, $95 \%$ within two standard deviations and $99.7 \%$ within three standard deviations.

Statisticians cannot guarantee $100 \%$ confidence level in their statements because $100 \%$ is not a confidence interval. This level may not match the general population because statisticians cannot collect data from everyone and to leave space for doubt. This finding shows that nonbelievers of Allah also, agree that uncertainties must be included in equations. Therefore, statisticians should include philosophy in logical equations.
Electrical signals and the heart: Prophet Mohammad (PBUH) said, "Indeed there is a piece of flesh which, if it be sound, all the body is sound and which if it be diseased, all of it is diseased. Truly it is the heart" (Al-Bukhari, Muslim). Does the heart mentioned in this hadith pertain to the spiritual or physical heart or both? We must determine how the physical heart functions to answer this question.

From October 2014-2016, the author was a member of the Computational Health Informatics group at the Institute of Biomedical Engineering, University of Oxford, United Kingdom. The author was assigned to work on big data in a healthcare project for two years. The project aimed to extract respiratory rate from ECG. Abnormalities in vital signs such as pulse rate, body temperature, blood pressure and respiratory rate, often predict a serious condition of acutely ill hospital patients within $24 \mathrm{~h}$. Many studies highlighted that fluctuations in respiratory rate are highly predictive of health deterioration and are used for early detection (Wang et al., 2013; Addison et al., 2012). Therefore, respiratory rate is an early indicator of physiological deterioration and should be recorded with other vital signs.

Many algorithms were proposed to estimate respiratory rate from several physiological signals such as the ECG, photoplethysmogram, accelerometry and impedance pneumography signals (Nayan et al., 2016). These signals can be easily measured and are already measured for other purposes in some scenarios.

Pacemaker cells that specialize in producing electricity can be found in the wall of the heart (myocardium). They produce electricity by quickly changing their electrical charge from positive to negative and back. They are connected to a network that allows electrical impulse to rapidly spread throughout the heart. The impulse triggers mechanical force during heart contraction. These biomedical signals, namely, electrical heart of ECG signals, contain information about the respiratory rate of patients (Sukor et al., 2011; Fleming and Tarassenko, 2007). Thus, respiratory signals are clinically discovered to modulate ECG.

The aim of this study is to prove that the deterioration of one's body can be detected by a signal generated by the heart, that is ECG signals. Then, we can conclude that the heart is the source of information for health deterioration as what is mentioned by Prophet Muhammad 1400 years ago.

\section{MATERIALS AND METHODS}

We created, tested and verified the most important algorithms to estimate respiratory rate from ECG. Raw ECG signals were used as algorithm inputs and estimated 


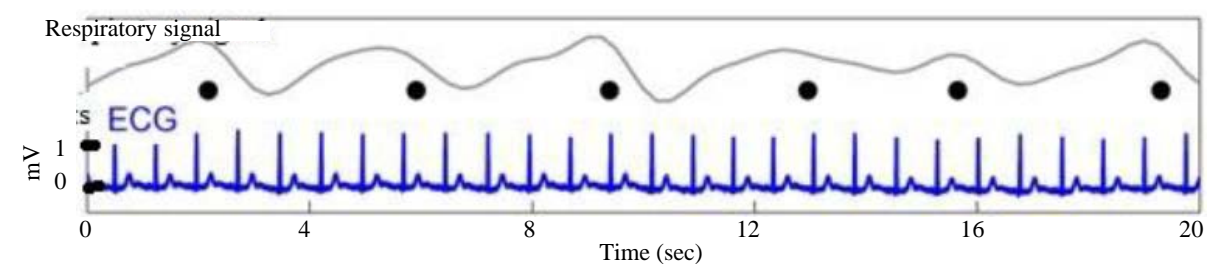

Fig. 3: Raw ECG signal and the respiratory signals

results were compared with the gold standard respiratory rate measurement to obtain the Mean Absolute Error (MAE) (Karlen et al., 2013).

The developed algorithms involve three steps. The first step is signal preprocessing which contains signal filtering such as baseline wander removal (Mneimneh et al., 2006; Fasano and Villani, 2014). The second step is the Signal Quality Index (SQI) evaluation which is performed before respiratory rate estimation (Orphanidou et al., 2015). The SQI process is used to select good signals for respiratory rate extraction. Selection is conducted using two different R-peak detectors developed by Zhang et al. (2006) and Behar et al. (2013). If both peak detectors agree with each other, the SQI is $>0.9$. Otherwise, it is $<0.9$. The third step involves the development of extraction algorithm (Nayan et al., 2015). The process starts from R-peak detection of the ECG signal (Johnson et al., 2014). The signals are divided into frequency or amplitude modulations after obtaining fiducial data. Each modulation performs spline interpolation at $4 \mathrm{~Hz}$ prior to fast Fourier transform process to detect the frequency of $0.1-0.6 \mathrm{~Hz}$ which is equal to human respiratory frequency. Transmission line frequency, that is $50 \mathrm{~Hz}$ is also removed by the algorithm (Zhao and Chen, 2006; Shirbani and Setarehdan, 2013). Respiratory signals extracted from the ECG are then plotted. Fusion algorithm is used to combine the two modulation signals (frequency and amplitude) into single respiratory rate data. Finally, the respiratory rate from the extraction is compared with the gold standard respiratory rate by generating the MAE.

The algorithms were validated using seven different patient datasets which also contains gold-standard respiratory signals. MIMПC-II dataset (784 patients) is an ICU admitted patient data at Beth Israel Deaconness Medical Center in Boston. CapnoBase (42 patients) is the work of Dr. Walter Karlen and his team at the University of British Columbia Canada in 2009. Dialysis 1 (96 patients), 2 (554 patients) and 3 (364 patients) are the data produced by Dr. David Clifton and his team at the University of Oxford, United Kingdom. Synthetic and
Vortal (74 patients) data are produced from the work of Dr. Peter Charlton and Dr. Tim Bonnici at St. Thomas Hospital, London.

\section{RESULTS AND DISCUSSION}

Results showed that respiratory rate estimation provides the MAE value of MIMIC-II which consist of 784 patients with $3.67 \mathrm{breath} / \mathrm{min}$. Besides the offline patient datasets, we also recorded ECG and nasal air flow volume of 20 healthy people using the acquisition system of a single lead ECG. Results show good MAE value at $2.05 \mathrm{breath} / \mathrm{min}$ for the new recorded dataset. Extracted respiratory (top black waveforms) and raw ECG signals (bottom blue waveforms) are shown in Fig. 3. The black dots in the figure indicate the time when the inhalation process takes place.

\section{CONCLUSION}

This study developed algorithms to extract respiratory information from ECG. The MAE value is between 2-3.6 breath $/ \mathrm{min}$ which proves that signals received from the heart, that is the ECG demonstrated by the respiratory rate, describes the current condition of our body condition. A good signal indicates good respiratory rate (between 12-25 per minute) has no serious health problems. Otherwise, health deterioration is possible. We can imply that science shows that the heart manages to warn us on our health condition which is consistent with the message delivered by the Prophet Mohammed, Messenger of Allah, more than 1,400 years ago.

\section{REFERENCES}

Addison, P.S., J.N. Watson, M.L. Mestek and R.S. Mecca, 2012. Developing an algorithm for pulse oximetry derived respiratory rate (RRoxi): A healthy volunteer study. J. Clin. Monit. Comput., 26: 45-51.

Behar, J., J. Oster, Q. Li and G.D. Clifford, 2013. ECG signal quality during arrhythmia and its application to false alarm reduction. IEEE. Trans. Biomed. Eng., 60: 1660-1666. 
Falagas, M.E., E.A. Zarkadoulia and G. Samonis, 2006. Arab science in the golden age (750-1258 C.E.) and today. FASEB. J., 20: 1581-1586.

Fasano, A. and V. Villani, 2014. Baseline wander removal for bioelectrical signals by quadratic variation reduction. Signal Process., 99: 48-57.

Fleming, S.G. and L. Tarassenko, 2007. A comparison of signal processing techniques for the extraction of breathing rate from the photoplethysmogram. Intl. J. Biol. Med. Sci., 2: 232-236.

Johnson, A.E.W., J. Behar, F. Andreotti, G.D. Clifford and J. Oster, 2014. R-peak estimation using multimodal lead switching. Proceedings of the International Conference on Computing in Cardiology ( CinC), September 7-10, 2014, IEEE, Cambridge, Massachusetts, USA., ISBN:978-1-4799-4346-3, pp: 281-284.

Karlen, W., S. Raman, J.M. Ansermino and G.A. Dumont, 2013. Multiparameter respiratory rate estimation from the photoplethysmogram. IEEE. Trans. Biomed. Eng., 60: 1946-1953.

Mneimneh, M.A., E.E. Yaz, M.T. Johnson and R.J. Povinelli, 2006. An adaptive Kalman filter for removing baseline wandering in ECG signals. Proceedings of the International Conference on Computers in Cardiology, September 17-20, 2006, IEEE, Valencia, Spain, ISBN:978-1-4244-2532-7, pp: 253-256.

Nayan, N.A., N.S. Risman and R. Jaafar, 2015. Breathing rate estimation from a single-lead electrocardiogram acquisition system. Intl. J. Appl. Eng. Res., 10: 38154-38158.

Nayan, N.A., N.S. Risman and R. Jaafar, 2016. A portable respiratory rate estimation system with a passive single-lead electrocardiogram acquisition module. Technol. Health Care, 24: 591-597.
Orphanidou, C., T. Bonnici, P. Charlton, D. Clifton and D. Vallance et al., 2015. Signal-quality indices for the electrocardiogram and photoplethysmogram: Derivation and applications to wireless monitoring. IEEE. J. Biomed. Health Inf., 19: 832-838.

Paul, G.S., 2005. Cross-national correlations of quantifiable societal health with popular religiosity and secularism in the prosperous democracies. J. Religion Soc., 7: 3-17.

Shirbani, F. and S.K. Setarehdan, 2013. ECG power line interference removal using combination of FFT and adaptive non-linear noise estimator. Proceedings of the 21st Iranian Conference on Electrical Engineering (ICEE), May 14-16, 2013, IEEE, Mashhad, Iran, ISBN:978-1-4673-5634-3, pp: $1-5$.

Sukor, J.A., S.J. Redmond and N.H. Lovell, 2011. Signal quality measures for pulse oximetry through waveform morphology analysis. Physiol. Meas., 32: 369-384.

Wang, C., Z. Li and X. Wei, 2013. Monitoring heart and respiratory rates at radial artery based on PPG. Intl. J. Light Electr. Optics, 124: 3954-3956.

Zhang, Q., A.I. Manriquez, C. Medigue, Y. Papelier and M. Sorine, 2006. An algorithm for robust and efficient location of $\mathrm{T}$-wave ends in electrocardiograms. IEEE. Trans. Biomed. Eng., 53: 2544-2552.

Zhao, Z.D. and Y.Q. Chen, 2006. A new method for removal of baseline wander and power line interference in ECG signals. Proceedings of the International Conference on Machine Learning and Cybernetics, August 13-16, 2006, IEEE, Dalian, China, China, ISBN:1-4244-0061-9, pp: 4342-4347. 